\title{
Effects of cortisol on chloride cells in the gill epithelium of Japanese eel, Anguilla japonica
}

\author{
C K C Wong and D K O Chan
}

Department of Zoology, University of Hong Kong, Hong Kong

(Requests for offprints should be addressed to C K C Wong, Department of Zoology, Kadoorie Biological Science Building, University of Hong Kong, Pokfulam Road, Hong Kong

\begin{abstract}
The purpose of the present study was to determine the effects of cortisol on the development of the freshwater chloride cell (CC), using flow cytometry. Scanning electron microscopy was used to determine the corresponding modifications in CC apical structure. Simultaneously, biochemical analyses were conducted to determine the activities of transport ATPases, mitochondrial enzymes (succinate dehydrogenase (SDH) and $\mathrm{Mg}^{2+}$-ATPase) and lactate dehydrogenase (Ldh). The effects of daily i.m. injection of $2 \mu \mathrm{g} / \mathrm{g}$ cortisol were compared with sham-injected freshwater-, control freshwater- and seawater-adapted fish. The hormone did not affect the activities of $\mathrm{Ca}^{2+}$-ATPases in CCs. However, it stimulated the proliferation and differentiation of the two freshwater CC subtypes (F1, $66 \pm 2 \cdot 18 \%$ (s.E.M.) and $\mathrm{F} 2,34 \pm 2 \cdot 18 \%$ ), in which the relative proportion of F1 CCs was transiently reduced in the first 5 days of
\end{abstract}

treatment (F1, $53 \pm 1 \cdot 83 \%$; F2, $47 \pm 1 \cdot 83 \%)$ but was then restored to a higher relative percentage on day 10 (F1, $70 \pm 1 \cdot 42 \%$; F2, $30 \pm 1 \cdot 42 \%)$. Biochemically, it induced the activities of $\mathrm{Na}^{+} / \mathrm{K}^{+}$-ATPase, $\mathrm{Mg}^{2+}$-ATPase, $\mathrm{SDH}$ and Ldh, suggesting an increase in ion pumping and its associated metabolic activities. CCs from cortisoltreated fish demonstrated recessed apical morphology, accompanied by an increase in cell density (2012 to $2413 / \mathrm{mm}^{2}$ ). Nevertheless, the extent of cell proliferation and differentiation and the biochemical changes were significantly lower than those of seawater fish. Our results indicate that cortisol alone cannot stimulate a complete differentiation of freshwater CCs to seawater CCs. However, the respective roles of the two CC subtypes in freshwater and seawater environments are indicated.

Journal of Endocrinology (2001) 168, 185-192

\section{Introduction}

Cortisol, a major corticosteroid factor secreted by the interrenal gland, has been proven to be important in hypo-osmoregulation in teleost fish (Mayer et al. 1967, Mommsen 1984, Madsen 1990). Its hormonal action may affect water and electrolyte transport in tissues of the gill, gut, kidney, urinary bladder and muscle, thereby influencing the concentration of electrolytes in blood and urine (Mayer et al. 1967, Henderson \& Garland 1980, Veillette et al. 1995). In the initial phase (first 5 days) of seawater acclimation, a marked transitory increase in plasma cortisol levels has been detected (Ball et al. 1971, Assem \& Hanke 1981). The duration of the elevated plasma cortisol level is correlated with morphological changes in the gill epithelium, whereby a drastic cellular and functional reorganization occurs to adjust to this short-term osmotic crisis (Chan \& Woo 1978, Chan et al. 1978, Chan \& Wong 1997). Within the first $4 \mathrm{~h}$ of acclimation, gill $\mathrm{Na}^{+}$ excretion activity is recruited, followed by an emergence of new (transitory) subtypes of chloride cell (CC) (Chan 1967, Wong \& Chan 1999a). In the next 2-4 days, there is a profound increase in the number and size of CCs, together with a marked increase in $\mathrm{Na}^{+} / \mathrm{K}^{+}$-ATPase activities and mitochondrial contents (Wong \& Chan 1999b). An enlargement of the CC apical pit was observed where $\mathrm{Cl}^{-}$was excreted. Accompanying the maturation of seawater CCs, normonatremia and normokalemia were restored.

Considerable numbers of studies have demonstrated that exogenous cortisol treatment stimulates $\mathrm{Na}^{+} / \mathrm{K}^{+}$-ATPase activities, mitochondrial content and cellular differentiation of both freshwater and seawater CCs (Laurent \& Perry 1990, Madsen 1990, McCormick 1990, Seidelin et al. 1999). They indicated that exogenous cortisol treatment can simulate biochemical and cellular modification as in the case of seawater acclimation. Recently the specific action of cortisol was addressed by the demonstration of cortisol receptor mRNA and immunity in gill CCs (Uchida et al. 1998). However, information on its possible effect in the regulation of different $\mathrm{CC}$ subtypes is limited. Our recently developed technique for CC subtype identification provides an excellent tool to study the cytological changes of these cells upon cortisol 
stimulation. It also provides good statistics by analysis of high numbers of cells. The freshwater (F1, F2), transitory (T1, T2) and seawater (S1, S2) CC subtypes defined in our previous study appeared sequentially during seawater acclimation. The F1 cell was the main subtype in freshwater gill. The cells were bigger in size, but contained lower levels of mitochondrial autofluorescence than F2. The T1 and $\mathrm{T} 2$ subtypes, which were of bigger cell size and more intense mitochondrial autofluorescence, appeared within 2-4 days of acclimation. The S1 and S2 were the largest subtypes with highest mitochondrial autofluorescence that emerged in seawater fish (Wong \& Chan 1999a). Hence they could be used as a reference to compare the corresponding CC subtypes induced by cortisol treatment, shedding light on the complex changes in gill CCs which are not accessible with conventional techniques. However, the main drawback of this technique is the lack of structural and biochemical information on the tissues. This limitation can partly be overcome by scanning electron microscopy (SEM) and biochemical analysis. The use of these techniques together could provide a better understanding on the effects of cortisol on CC differentiation.

\section{Materials and Methods}

\section{Animals}

Japanese eels (Anguilla japonica) weighing between 500 and $600 \mathrm{~g}$, were reared in fiberglass tanks supplied with charcoal-filtering aerated tap-water at $18-20{ }^{\circ} \mathrm{C}$ under a $12 \mathrm{~h}$ light: $12 \mathrm{~h}$ darkness photoperiod for at least 3 weeks. Since the fish were sexually immature (gonadosomatic index $\leq 0 \cdot 18 \%$ ), mixed sexes were used to prepare gill cells for this study. Freshwater-adapted eels $(n=32)$ received daily i.m. injections of cortisol (hydrocortisone 21-hemisuccinate sodium salt; $2 \mu \mathrm{g} / \mathrm{g}$ body weight) dissolved in $0.1 \mathrm{ml} 0.9 \%(\mathrm{w} / \mathrm{v}) \mathrm{NaCl}$. The fish were anesthetized in $0.05 \%$ tricaine methanesulfonate and killed at predetermined intervals (day 2, 5 and 10) by spinosectomy according to the animal care regulations of the University. Three control groups were used including one negative control group and one sham ( $\mathrm{NaCl}$-injected) group maintained in freshwater, while one positive control group was transferred from freshwater to seawater for 10 days.

\section{Cell isolation and flow cytometric analysis}

Gill cells were isolated using a three-step discontinuous percoll gradient system described previously (Wong \& Chan 1999b). Flow cytometric analysis was performed on a Coulter (Hong Kong) EPICS Elite Flow Cytometer (FCM), equipped with an Argon laser $(15 \mathrm{~mW})$ emitting at $488 \mathrm{~nm}$. The instrument had a standard optical filter configuration with band pass 530/30 nm and 585/42 nm filters for FL1 and FL2 respectively, and a $610 \mathrm{~nm}$ band pass filter for FL3. The FCM was calibrated before use with standard DNA beads.

Isolated gill cells (about $10^{6}$ cells $/ \mathrm{ml}$ in Hanks' balanced salts solution (HBSS)) were analyzed directly by FCM. The change in cell size (forward light scatter (FLS)), and autofluorescence at $525 \mathrm{~nm}$ (FL1) were recorded. Individual cell population was sorted to reconfirm the cell type identification, using mitochondrial staining. Briefly, the sorted cells were stained by incubation with $1 \mu \mathrm{M}$ rhodamine-123 for about $45 \mathrm{~min}$. After washing in $10 \mathrm{mM}$ PBS, the preparation was examined (excitation $488 \mathrm{~nm}$, emission $512 \mathrm{~nm}$ ) in a laser confocal microscope using an Argon light source (MRC-600; BioRad). The cells showed intense mitochondrial staining, indicating their identity as CCs.

\section{Cell sizing and counting}

Freshwater-adapted eels $(n=28)$ received daily i.m. injections of cortisol ( $2 \mu \mathrm{g} / \mathrm{g}$ body weight) and were killed at predetermined intervals (day 2, 5 and 10). Isolated CCs were counted and sized using a Coulter Multisizer II, with an orifice tube of $70 \mu \mathrm{m}$ in diameter and with isoton II as electrolyte. The cell count signal was the change of conductance of the electrolyte induced by particle resistance. Isoton II was used as blank and calibration was carried out with monodiameter particles (PDVB latex $5.06 \mu \mathrm{m}$; Coulter). The aperture coincidence correction was below $2 \%$.

\section{SEM and morphometric measurements}

The excised gill arch was fixed overnight in 2.5\% glutaraldehyde in HBSS at room temperature. After dehydration in ethanol and critical point drying with $\mathrm{CO}_{2}$, the tissue was mounted onto aluminum stubs and coated with gold-palladium. The preparation was then examined under a Leica Steroscan-440 SEM. The area of the filament epithelium on the trailing edge of the filaments was focused and photographed at a magnification of $1000 \times$. At least five non-contiguous fields were randomly photographed from each fish for morphometric analysis. Measurement of the apical surface areas of CCs was accomplished using SEM and morphometry software (Quantimet 500C; Leica, Germany).

\section{Biochemical analysis}

Freshwater-adapted eels were pretreated with daily $2 \mu \mathrm{g} / \mathrm{g}$ cortisol injection for 10 days. $\mathrm{Na}^{+} / \mathrm{K}^{+}$-ATPase, $\mathrm{Mg}^{2+}{ }_{-}$ ATPase, alkaline $\mathrm{Ca}^{2+}$-ATPase, low- and high-affinity $\mathrm{Ca}^{2+}$-ATPases, succinate dehydrogenase (SDH) and lactate dehydrogenase (Ldh) activities in isolated CCs were 
determined as described before (Chan \& Wong 1997, Wong \& Chan 1999b).

\section{Statistical analysis}

All data are represented as means \pm S.E.M. Statistical significance was tested by ANOVA followed by Duncan's multiple range test. The level of significance was set at a $P$ value of $<0 \cdot 05$.

\section{Results}

\section{FCM and cell-sizing analysis}

In freshwater control fish, two CC subtypes, F1 and F2, were identified (Fig. 1A). The F1 CC was bigger in size but lower in autofluorescence than the F2 CC. The relative proportions of these two cell subtypes were $66 \pm 2 \cdot 18$ and $34 \pm 2 \cdot 18 \%$ respectively. Chronic daily injection of $2 \mu \mathrm{g} / \mathrm{g}$ cortisol stimulated the proliferation and differentiation of freshwater CCs. On day 10 of cortisol treatment, the yield of CCs was increased by about 2 -fold $\left(2.96 \pm 0.22 \times 10^{5}\right.$ to $\left.6.37 \pm 0.43 \times 10^{5}\right)($ Table 1$)$. The mean cell size and mitochondrial autofluorescence of both $\mathrm{F} 1$ and $\mathrm{F} 2 \mathrm{CCs}$ were also increased (Fig. 1B-D). In addition to the cytological changes, an adjustment in the relative proportion of F1 and F2 CCs was observed. In the first 5 days of treatment, there was a transient reduction and induction of the relative percentage of $F 1$ (decrease from $66 \pm 2 \cdot 18$ to $53 \pm 1 \cdot 83 \%$ ) and F2 CCs (increase from $34 \pm 2 \cdot 18 \%$ to $47 \pm 1 \cdot 83 \%$ ) respectively. However, on day 10, the F1 CCs increased back to a higher percentage of about $70 \pm 1.42 \%$ whereas F2 CCs decreased to $30 \pm 1 \cdot 42 \%$. The size and mitochondrial autofluorescence of the F1 and F2 CCs from cortisol-treated fish were considerably lower compared with the S1 $(50 \pm 2 \cdot 01 \%)$ and S2 $(49 \pm 2 \cdot 01 \%)$ CCs in seawater fish (Fig. 1F). There were no noticeable cytological changes in the F1 $(67 \pm 1 \cdot 72 \%)$ and F2 $(33 \pm 1 \cdot 72 \%)$ CCs in the sham group (Fig. 1E), indicating that saline injection had no prominent stimulatory effect on the differentiation of freshwater CCs.

\section{SEM}

Figure 2 shows representative SEMs illustrating the external surfaces of the primary gill lamellae. They were covered by the most abundant cell type, pavement cells (PVCs) which showed concentrically arranged microridges on their surfaces, while CCs were relatively scarce with characteristic apical area extrusions extending out between PVCs. In freshwater fish (Fig. 2A), CCs displayed characteristic convex apical surfaces with abundant microvilli. In seawater-adapted fish (Fig. 2B), the apical surface of CCs contained less microvilli and was recessed below the surface of neighboring PVCs. In 10-day cortisol-treated freshwater-adapted eels, the exposed apical surface of CCs showed abundant microvilli; however, it demonstrated recessed apical morphology compared with the convex appearance in freshwater control fish. Quantitatively, there was a significant increase in the density of CCs from the cortisol-treated group (Table 2), resulting in an increase in the total CC fractional area (CCFA: individual CC apical membrane area $\times$ the density of CCs per unit $\mathrm{mm}^{2}$ ). The increase may be due to the retraction of neighboring PVCs or swelling of the CCs themselves (Fig. 2C-F).

\section{Biochemical analyses}

To quantify the changes in transport ATPase, mitochondrial and metabolic enzymes in association with the cytological changes of CCs, the activities of $\mathrm{Na}^{+} / \mathrm{K}^{+}$ ATPase, alkaline $\mathrm{Ca}^{2+}$-ATPase, low- and high-affinity $\mathrm{Ca}^{2+}$-ATPases, $\mathrm{Mg}^{2+}$-ATPase, $\mathrm{SDH}$ and $\mathrm{Ldh}$ were determined (Table 3). The $\mathrm{Na}^{+} / \mathrm{K}^{+}$-ATPase, $\mathrm{Mg}^{2+}$ ATPase, $\mathrm{SDH}$ and Ldh activities increased significantly in the cortisol-treated group. No significant changes in the activities of $\mathrm{Ca}^{2+}$-ATPases were detected.

\section{Discussion}

FCM analysis showed the effect of exogenous cortisol in exerting a stimulatory effect on both CC subtypes, inducing cell proliferation and differentiation. There were approximately 2.3- and 1.9-fold increases of F1 and F2 CC numbers respectively, after 10 days of cortisol treatment. The newly synthesized CCs were possibly derived from the stem cells in the gill interlamellar region (Uchida et al. 1998, Wong \& Chan 1999a). Accompanying cell proliferation, a two-phase adaptational change in the two freshwater CC subtypes was observed. The first phase of cortisol injection (day 1-5) activated the hypo-osmotic responses of gill epithelia in which the relative percentage of F1 CCs decreased from 66 to 53\% while F2 CCs increased from 34 to $47 \%$. The change may be similar to the initial phase of seawater adaptation as described in our previous study in which a reduction of F1 (67.5 to 29\%) and an induction of F2 (32.5 to 35.5\%) CCs were observed (Wong \& Chan 1999a). Other studies have also reported a decrease of $\beta$, A or lamellar CCs and an increase in $\alpha, \mathrm{B}$ or filamental $\mathrm{CCs}$ during seawater acclimation (Shirai \& Utida 1970, Pisam \& Rambourg 1991, Uchida et al. 1996, Shikano \& Fujio 1998). The F1 and $\beta$ cells were suggested to be specifically involved in freshwater adaptation while the F2 and $\alpha$ cells were postulated to be differentiated into seawater CCs (Pisam et al. 1993, Shikano \& Fujio 1998, Wong \& Chan 1999a). Likewise, it was hypothesized that the lamellar CC was active in ion-absorption in freshwater while the filamental CC 

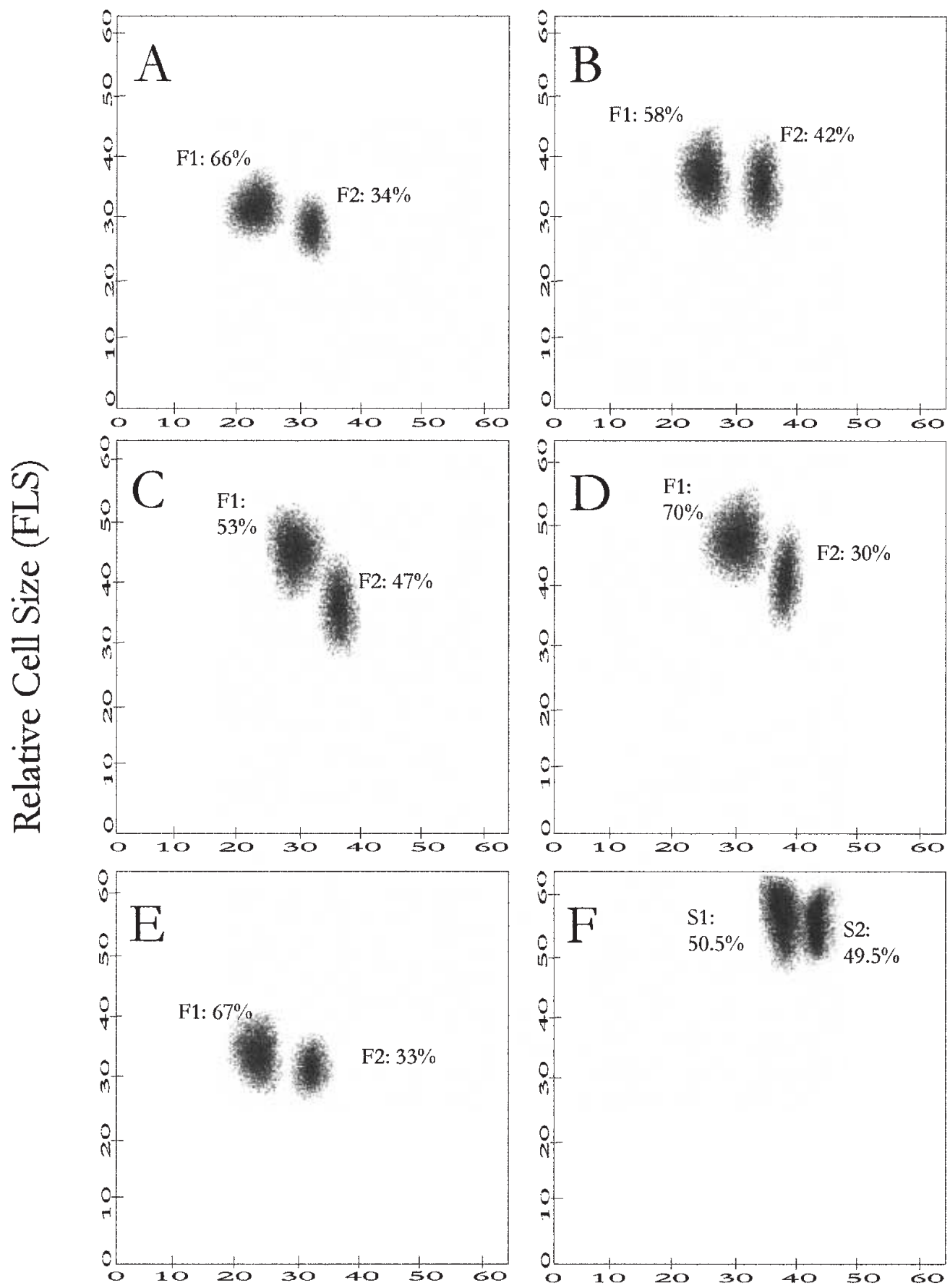

\section{Autofluorescence (FL1)}

Figure 1 Representative FLS vs FL1 dot plots of CC subtypes isolated from gill epithelia of (A) freshwater control fish and (B) 2nd day, (C) 5th day, (D) 10th day of cortisol- and sham- (E) injected fish. It was obtained by analyzing isolated gill CCs $\left(\sim 10^{6}\right.$ cells $/ \mathrm{ml}$ in HBSS) with a Coulter EPICS Elite flow cytometer. (F) Cells isolated from seawater fish. F1 and F2, freshwater, S1 and S2, seawater CC subtypes. 
Table 1 The effects of $2 \mu \mathrm{g} / \mathrm{g}$ cortisol treatment on number and mean size ( \pm S.E.M.) of CCs isolated from gill epithelia

\begin{tabular}{|c|c|c|c|c|c|c|}
\hline & \multirow[b]{2}{*}{ Freshwater } & \multirow[b]{2}{*}{ Sham } & \multicolumn{3}{|c|}{ Cortisol treated } & \multirow[b]{2}{*}{ Seawater } \\
\hline & & & Day 2 & Day 5 & Day 10 & \\
\hline Number of fish.... & 4 & 4 & 5 & 5 & 6 & 4 \\
\hline $\mathrm{CC}$ number $\left(\times 10^{5}\right)$ & $2 \cdot 96 \pm 0 \cdot 22$ & $3 \cdot 21 \pm 0 \cdot 28$ & $4 \cdot 22 \pm 0 \cdot 37^{*}$ & $5 \cdot 82 \pm 0 \cdot 44^{*}$ & $6 \cdot 37 \pm 0.43^{*}$ & $32 \cdot 5 \pm 0 \cdot 24^{*}$ \\
\hline Mean cell size $(\mu \mathrm{m})$ & $11.6 \pm 0.64$ & $11 \cdot 7 \pm 0 \cdot 72$ & $12 \cdot 5 \pm 0 \cdot 59$ & $13 \cdot 2 \pm 1 \cdot 02^{*}$ & $13 \cdot 6 \pm 0.94^{*}$ & $15 \cdot 3 \pm 0 \cdot 48^{*}$ \\
\hline
\end{tabular}

${ }^{*} P<0.05$ compared with corresponding value in freshwater eels.

participated in ion-secreting activities in seawater (Uchida et al. 1996, Seidelin \& Madsen 1999). Therefore in the present study, the results suggested that the initial phase of cortisol treatment stimulated the proliferation and differentiation of stem cells and F2 CCs, in promoting the hypo-osmoregulatory function of the gill epithelium. This might result in a negative regulatory effect on the F1 CC. In the second phase of cortisol treatment, however, a restoration of the $\mathrm{F} 1 \mathrm{CC}$ to a higher relative percentage was observed. The discrepancy compared with the first phase of treatment could possibly be a result of the long-term cortisol administration that may cause secondary regulatory mechanisms or functions which nullify or change the effect of the hormone (Chan \& Woo 1978, Flik \& Perry 1989, Laurent \& Perry 1990, Perry et al. 1992). The opposite responses of the two freshwater CC subtypes in the two phases of treatment implied their different functions in freshwater and seawater conditions (Pisam et al. 1993, Shikano \& Fujio 1998, Uchida et al. 1998, Seidelin \& Madsen 1999, Wong \& Chan 1999a).

The FCM analysis resolved the two freshwater CC subtypes and characterized statistically the effects of cortisol on their development. However, no information on the functional activities of CCs was obtained. This limitation could be partly overcome by a study of the CC apical surface, a primary site of ionic transport, to give a better understanding of the specific action of the hormone. Therefore in the second part of the study, SEM and morphometric quantification were conducted to determine the changes in CC density as well as its apical surface area on gill epithelium. Our results indicated that cortisol stimulated a $\sim 26 \%$ increase in total CCFA, resulting from a $\sim 20 \%$ increase in CC density compared with the seawater fish in which a $\sim 39 \%$ increase in CCFA was contributed by a $\sim 47 \%$ increase in CC density. An increase in total CCFA upon cortisol treatment implied the possibility of an activation of $\mathrm{CC}$ ion transport activities (i.e. $\mathrm{Na}^{+}$or $\mathrm{Ca}^{2+}$ uptake) (Flik \& Perry 1989, Laurent \& Perry 1990, Perry et al. 1992). Laurent \& Perry (1990) reported that long-term cortisol treatment could stimulate the abundance of lamellar CCs in promoting ionabsorbing activities. A similar observation was reported in which 10-day cortisol $(4 \mu \mathrm{g} / \mathrm{g})$ injection stimulated an increase of CC apical surface area in gill epithelia of the American eel in facilitating gill $\mathrm{Ca}^{2+}$-uptake (Perry et al. 1992).

The different responses of the two freshwater CC subtypes and the upregulation of transport ATPases were demonstrated; however, biochemical aspects of the mechanisms supplying the required ATP for the former processes have been largely neglected. Chan \& Woo (1978) demonstrated that transfer of eels to seawater or under cortisol $(1 \mu \mathrm{g} / \mathrm{g})$ treatment caused a marked but transient increase in blood glucose concentration, suggesting stimulation of the utilization of carbohydrate substrates. Analysis of metabolite concentrations across gill epithelia revealed that gill cells had a preference for using lactate and glucose as oxidative substrates (Mommsen 1984). It suggested that Ldh was important in mediating energy balance, in particular of transepithelial ion transport. In fact, the induction of $\mathrm{Na}^{+} / \mathrm{K}^{+}$-ATPase activities and CCFA in cortisol-treated fish was accompanied by an upregulation of the mitochondrial enzymes (SDH and $\mathrm{Mg}^{2+}$-ATPase) as well as the metabolic enzyme, Ldh. Our previous finding showed that $\mathrm{CCs}$ expressed predominantly $\mathrm{Ldh}_{-} \mathrm{B}_{4}$ isozyme, indicating that the process depended on aerobic metabolism (Wong 1996).

In summary, it is obvious that cortisol exerted a stimulatory effect on CCs, along with the upregulation of transport ATPases, Ldh and mitochondrial enzymes. However, the extent of cellular differentiation and proliferation were considerably less than that in seawater, in which a drastic increase in CC number, mitochondrial content and cellular complexity was observed (Wong \& Chan 1999b). In addition transitory CC subtypes, which appeared on the first 3 days of seawater adaptation, were not found after cortisol treatment (Wong \& Chan 1999a). The disparities indicated that exogenous cortisol treatment alone could not evoke the complete differentiation and maturation of seawater CCs. In fact during seawater acclimation, a surge in growth hormone level has been reported, which could induce the expression of cortisol receptors in gill CCs (Sakamoto \& Hirano 1993, Shrimpton et al. 1995, Uchida et al. 1998). This, together with an elevated plasma cortisol in the initial phase of seawater adaptation, might synchronously stimulate the 

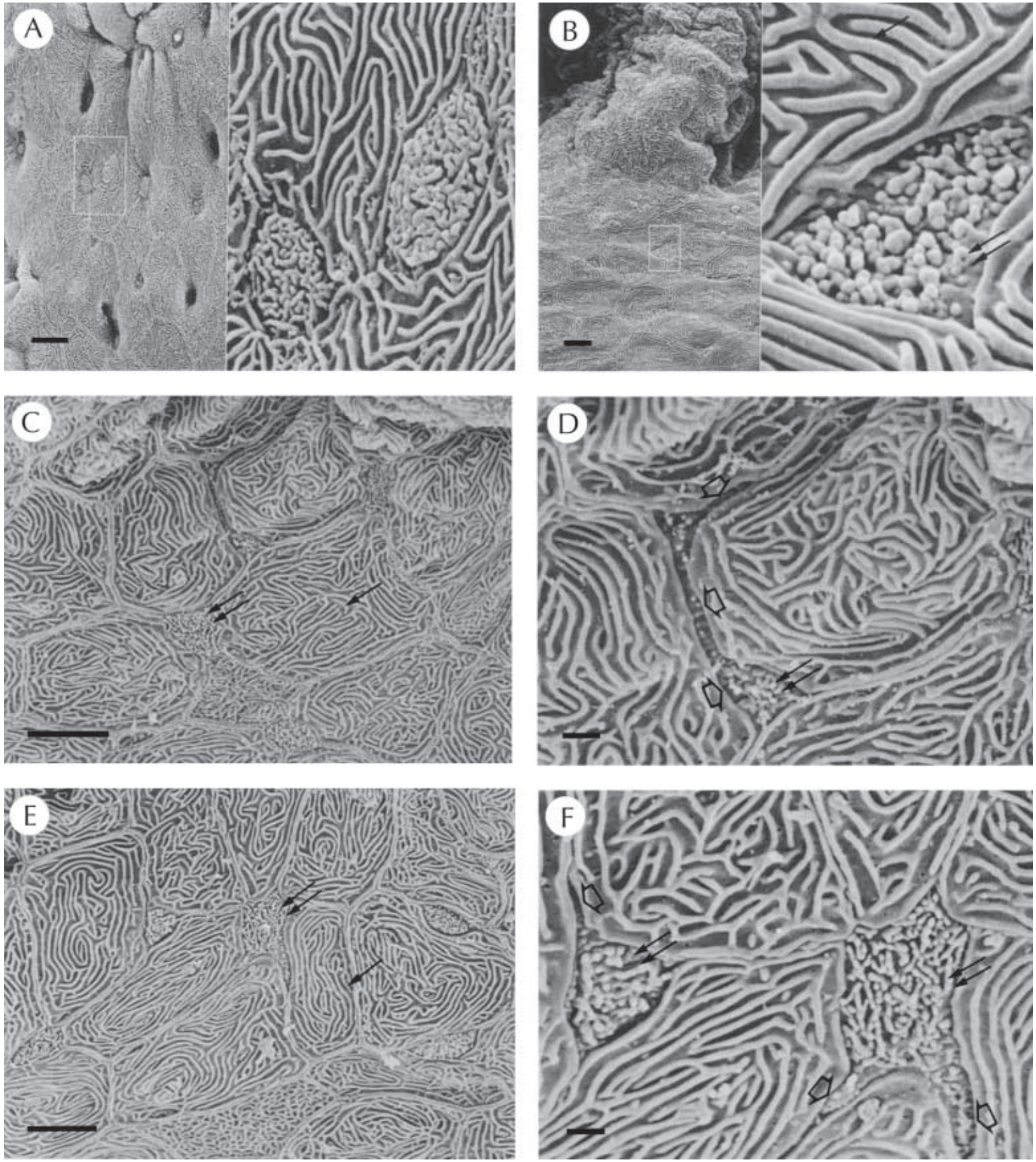

Figure 2 Representative SEMs of the filamental epithelia of (A) freshwater- and (B) seawater-adapted eels. PVCs and CCs are characterized by the microridge (single arrow) and microvilli (double arrows) appearance, respectively. Note the freshwater CCs displayed a convex apical surface with abundant microvilli whereas seawater CCs contained less microvilli and were recessed below the surface of neighboring PVCs. Apical surface of CCs from 10-day cortisol-treated fish (C) and (E) Sham-treated fish illustrate abundant microvilli as well as recessed apical morphology. Note the retraction of neighboring PVCs or swelling of the CC itself (open arrowheads). Panels $(D)$ and $(F)$ are higher magnification of $(C)$ and $(E)$ respectively. The scale bars in $(A-C, E)$ represent $5 \mu \mathrm{m}$; scale bars in $(D, F)$ represent $1 \mu \mathrm{m}$. 
Table 2 The effects of 10 days of $2 \mu \mathrm{g} / \mathrm{g}$ cortisol treatment on CC density, apical area and fractional area (means \pm S.E.M.) of gill CCS. Apical area refers to mean apical area of individual CCs

\begin{tabular}{|c|c|c|c|c|}
\hline & $n$ & $\begin{array}{l}\text { CC density } \\
\left(\text { per } \mathrm{mm}^{2}\right)\end{array}$ & $\begin{array}{l}\text { Apparent exposed CC } \\
\text { apical area }\left(\mu \mathrm{m}^{2}\right)\end{array}$ & CCFA (\%) \\
\hline Freshwater & 4 & $2012 \pm 182^{c}$ & $10 \cdot 28 \pm 1 \cdot 13$ & $2 \cdot 07 \pm 0 \cdot 18^{b}$ \\
\hline Sham-treated & 5 & $2053 \pm 165^{c}$ & $10 \cdot 31 \pm 1 \cdot 23$ & $2 \cdot 12 \pm 0 \cdot 20^{b}$ \\
\hline Cortisol-treated & 6 & $2413 \pm 201^{b}$ & $10 \cdot 83 \pm 1 \cdot 18$ & $2 \cdot 61 \pm 0 \cdot 27^{a}$ \\
\hline Seawater & 4 & $2964 \pm 264^{a}$ & $9.68 \pm 0.95$ & $2 \cdot 87 \pm 0 \cdot 25^{a}$ \\
\hline
\end{tabular}

Data with the same letter superscript in the same column are not significantly different according to the results of one-way ANOVA followed by Duncan's multiple range test $(P<0 \cdot 05)$.

Table 3 The effects of 10 days of $2 \mu \mathrm{g} / \mathrm{g}$ cortisol treatment on transport ATPase, SDH and Ldh (means \pm S.E.M.) in isolated gill CCs

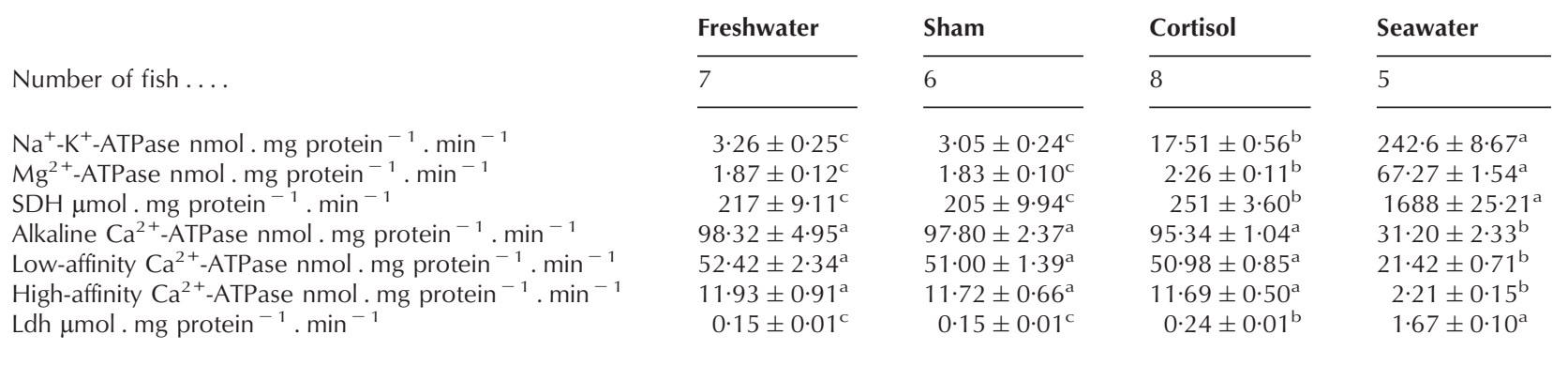

Data with the same letter superscript in the same row are not significantly different according to the results of one-way ANOVA followed by Duncan's multiple range test $(P<0 \cdot 05)$.

complete differentiation and maturation of seawater CCs (Ball et al. 1971, Assem \& Hanke 1981, Seidelin et al. 1999). However, in the present study, the cortisol-treated fish were maintained in a freshwater environment, therefore CCs were not necessarily equipped with substantially high levels of mitochondrial and transport ATPases for $\mathrm{Na}^{+}$and $\mathrm{Cl}^{-}$excretion. As demonstrated by Foskett \& Hubbard (1981), cortisol injection increased the density of CCs in the opercular membrane of freshwater fish; however, no chloride secretion was activated. In addition, long-term cortisol injection alone may cause a downregulation of cortisol receptors in the gill CC (Shrimpton \& Randall 1994). In the absence of a growth hormone surge to limit the decline in cortisol receptors (Shrimpton et al. 1994), the extent of CC proliferation and differentiation were attenuated. Despite the interpretation stated above, the limitation in the present study of utilizing three separate analytical approaches including (i) FCM, (ii) biochemical methods to analyze the isolated CC, and (iii) SEM to examine the trailing edge CCs, should be addressed. The difficulty in integrating results from these approaches is the inability to relate the particular CC subtypes to their respective locations in gill epithelia. It is possible that our interpretation would be at variance with the results of such an investigation.

\section{Acknowledgements}

This work was supported by the Research Grants Council, Hong Kong.

\section{References}

Assem H \& Hanke W 1981 Cortisol and osmotic adjustment of the euryhaline teleost, Sarotherodon mossambicus. General and Comparative Endocrinology 43 370-380.

Ball JN, Chester Jones I, Forster ME, Hargreaves G, Hawkins EF \& Milne KP 1971 Measurement of plasma cortisol levels in the eel Anguilla anguilla in relation to osmotic adjustments. Journal of Endocrinology $5075-96$.

Chan DKO 1967 Hormonal and haemodynamic factors controlling water and electrolyte balance in the European eel, Anguilla anguilla L. PhD Thesis, University of Sheffield.

Chan DKO \& Wong CKC 1997 Functional partition of cells in the gill epithelium of the Japanese eel, Anguilla japonica, and the role of hormones. Fish Physiology and Biochemistry 17 405-413.

Chan DKO \& Woo NYS 1978 Effect of cortisol on the metabolism of the eel, Anguilla japonica. General and Comparative Endocrinology 35 205-215.

Chan DKO, Ho SM \& So STC 1978 Adaptation to salinity changes in the eel Anguilla japonica: effects on respiratory and intermediary metabolism and the role of hormones. In Comparative Endocrinology, pp 227-230. Eds PJ Gaillard \& HH Boer. Amsterdam: ElsevierNorth Holland Biomedical Press. 
Flik G \& Perry SF 1989 Cortisol stimulates whole body calcium uptake and the branchial calcium pump in freshwater rainbow trout. Journal of Endocrinology 120 75-82.

Foskett JK \& Hubbard GM 1981 Hormonal control of chloride excretion by teleost opercular membrane. Annals of the New York Academy of Sciences 372643.

Henderson IW \& Garland HO 1980 The interrenal gland in Pisces. Part 2. Physiology. In General, Comparative and Clinical Endocrinology of the Adrenal Cortex, vol 3, pp 473-523. Eds I Chester Jones \& IW Henderson. New York/London: Academic Press.

Laurent P \& Perry SF 1990 Effects of cortisol on gill chloride cell morphology and ionic uptake in the freshwater trout, Salmo gairdneri. Cell and Tissue Research 259 429-442.

Madsen SS 1990 The role of cortisol and growth hormone in seawater adaptation and development of hypoosmoregulatory mechanisms in sea trout parr (Salmo trutta trutta). General and Comparative Endocrinology 79 1-11.

Mayer N, Maetz J, Chan DKO, Forster M \& Chester-Jones I 1967 Cortisol, a sodium excreting factor in the eel (Anguilla anguilla L.) adapted to sea water. Nature 214 1118-1120.

McCormick SD 1990 Cortisol directly stimulates differentiation of chloride cells in tilapia opercular membrane. American Journal of Physiology 259 R857-R863.

Mommsen TP 1984 Biochemical characterization of the rainbow trout gill. Journal of Comparative Physiology 154B 191-198.

Perry SF, Goss GG \& Fenwick JC 1992 Interrelationships between gill chloride cell morphology and calcium uptake in freshwater teleosts. Fish Physiology and Biochemistry 10 327-337.

Pisam M \& Rambourg A 1991 Mitochondria-rich cells in the gill epithelium of teleost fishes: an ultrastructural approach. International Review of Cytology 130 191-232.

Pisam M, Auperin B, Prunet P, Rentier-Delrue F, Martial J \& Rambourg A 1993 Effects of prolactin on $\alpha$ and $\beta$ chloride cells in the gill epithelium of the saltwater adapted tilapia Oreochromis niloticus. Anatomical Record 235 275-284.

Sakamoto T \& Hirano T 1993 Expression of insulin-like growth factor I gene in osmoregulatory organs during seawater adaptation of the salmonid fish: possible mode of osmoregulatory action of growth hormone. PNAS 90 1912-1916.

Seidelin M \& Madsen SS 1999 Endocrine control of $\mathrm{Na}^{+}, \mathrm{K}^{+}$-ATPase and chloride cell development in brown trout (Salmo trutta): interaction of insulin-like growth factor-I with prolactin and growth hormone. Journal of Endocrinology 162 127-135.

Seidelin M, Madsen SS, Byrialsen A \& Kristiansen K 1999 Effects of insulin-like growth factor-I and cortisol on $\mathrm{Na}^{+}, \mathrm{K}^{+}$-ATPase expression in osmoregulatory tissues of brown trout (Salmo trutta). General and Comparative Endocrinology 113 331-342.
Shikano T \& Fujio Y 1998 Relationships of salinity tolerance to immunolocalization of $\mathrm{Na}^{+}, \mathrm{K}^{+}$-ATPase in the gill epithelium during seawater and freshwater adaptation of the guppy, Poecilia reticulata. Journal of Experimental Zoology 281 80-89.

Shirai N \& Utida S 1970 Development and degeneration of the chloride cell during seawater and freshwater adaptation of the Japanese eel, Anguilla japonica. Zeitschrift Fur Zellforschung und Mikroskopische Anatomie 103 247-264.

Shrimpton JM \& Randall DJ 1994 Downregulation of corticosteroid receptors in the gills of coho salmon due to stress and cortisol treatment. American Journal of Physiology 267 R 432-438.

Shrimpton JM, Bernier NJ \& Randall DJ 1994 Changes in cortisol dynamics in wild and hatchery-reared juvenile coho salmon (Oncorhynchus kisutch) during smoltification. Canadian Journal of Fisheries and Aquatic Science 51 2179-2187.

Shrimpton JM, Devlin RH, McLean E, Byatt JC, Donaldson EM \& Randall DJ 1995 Increases in gill cytosolic corticosteroid receptor abundance and saltwater tolerance in juvenile coho salmon (Oncorhynchus kisutch) treated with growth hormone and placental lactogen. General and Comparative Endocrinology 98 1-15.

Uchida K, Kaneko T, Yamauchi K \& Hirano T 1996 Morphological analysis of chloride cell activity in the gill filaments and lamellae and changes in $\mathrm{Na}^{+}, \mathrm{K}^{+}$-ATPase activity during seawater adaptation in chum salmon fry. Journal of Experimental Zoology 276 193-200.

Uchida K, Kaneko T, Tagawa M \& Hirano T 1998 Localization of cortisol receptor in branchial chloride cells in chum salmon fry. General and Comparative Endocrinology 109 175-185.

Veillette PA, Sundell K \& Specker JL 1995 Cortisol mediates the increase in intestinal fluid absorption in Atlantic salmon during parr-smolt transformation. General and Comparative Endocrinology 97 250-258.

Wong CKC 1996 Functional and morphometric study of the isolated chloride and respiratory cell from the gill epithelium of the Japanese eel, Anguilla japonica. PhD Thesis, University of Hong Kong.

Wong CKC \& Chan DKO 1999a Chloride cell subtypes in the gill epithelium of Japanese eel Anguilla japonica. American Journal of Physiology 277 R517-R522.

Wong CKC \& Chan DKO 1999 b Isolation of viable cell types from the gill epithelium of Japanese eel Anguilla japonica. American Journal of Physiology 276 R363-R372.

Received 17 April 2000

Revised manuscript received 28 July 2000

Accepted 6 September 2000 